\title{
Effects of optimal pacing strategies for 400-, 800-, and 1500-m races on the $\mathrm{KO}_{2}$ response
}

\author{
CHRISTINE HANON \& CLAIRE THOMAS
}

Mission recherche, INSEP, Paris, France

\begin{abstract}
The aim of this study was to compare the evolution of oxygen uptake $\left(\mathrm{K} \mathrm{O}_{2}\right)$ in specifically trained runners during running tests based on the 400-, 800-, and $1500-\mathrm{m}$ pacing strategies adopted by elite runners to optimize performance. Final velocity decreased significantly for all three distances, with the slowest velocity in the last $100 \mathrm{~m}$ expressed relative to the peak velocity observed in the $400 \mathrm{~m}(77 \%), 800 \mathrm{~m} \mathrm{(88 \% ),} \mathrm{and} 1500 \mathrm{~m}(96 \%)$. Relative to the previously determined $\mathrm{V} \mathrm{O} \mathrm{O}_{2 \mathrm{max}}$ values, the respective $\mathrm{KO}_{2 \text { peak }}$ corresponded to $94 \%(400 \mathrm{~m})$ and $100 \%$ (800 and $\left.1500 \mathrm{~m}\right)$. In the last $100 \mathrm{~m}$, a decrease in $\mathrm{KO}_{2}$ was observed in all participants for the 400-m $(15.6+6.5 \%)$ and $800-\mathrm{m}$ races $(9.9+6.3 \%)$, whereas a nonsystematic decrease $(3.6+7.6 \%)$ was noted for the $1500 \mathrm{~m}$. The amplitude of this decrease was correlated with the reduction in tidal volume recorded during the last $100 \mathrm{~m}$ of each distance $\left(r^{1 / 4} 0.85, P 50.0001\right)$ and with maximal blood lactate concentrations after the three races $\left(r^{1} / 40.55, P 50.005\right)$. The present data demonstrate that the $800 \mathrm{~m}$ is similar to the $400 \mathrm{~m}$ in terms of decreases in velocity and $\mathrm{KO}_{2}$.
\end{abstract}

Keywords: Pacing strategy, oxygen uptake, running, performance

\section{Introduction}

The strategy of pacing, defined as varying the speed throughout a race by regulating the rate of energy expenditure (Foster, Schrager, \& Snyder, 1994), is proposed to be a marker of underlying physiological regulation (Tucker \& Noakes, 2009). When compared directly, the performances of gold, silver, and bronze medallists are within $1 \%$ of each other and even small variations in pacing strategy may have marked effects on race outcome (de Koning, Bobbert, \& Foster, 1999). Of the competitive athletics distances, only the 400-, 800-, and 1500$\mathrm{m}$ races require substantial contributions from the both aerobic and anaerobic systems (Hill, 1999), due to high relative values of oxygen uptake $\left(\mathrm{KO}_{2}\right)$ (Hanon, Lepretre, Bishop, \& Thomas, 2010; Hanon, Leveque, Thomas, \& Vivier, 2008; Thomas et al., 2005) and blood lactate concentrations above 15 mmol $\cdot \mathrm{L}^{71}$ that have been reported previously (Hill, 1999; Lacour, Bouvat, \& Barthélémy, 1990). Thus, an analysis of the optimal pacing strategies during these particular athletics events potentially could inform coaches and researchers, and provide insight into the underlying physiological processes involved in the performance.
Few studies have focused on the pacing strategies used in athletics competitions. In studying the pacing strategies adopted during world-record performances in 800-, 5000-, and 10,000-m races, Tucker and colleagues (Tucker, Lambert, \& Noakes, 2006) noted key differences between the $800 \mathrm{~m}$, for which the second lap was significantly slower than the first lap, and the $5000 \mathrm{~m}$ and $10,000 \mathrm{~m}$, where an end spurt was observed due to the maintenance of a reserve during the middle part of the races. From an energetics point of view, the 800- and 5000-m races appeared to be regulated differently. Hanon and Gajer (2009) described the pacing strategies used by elite 400-m runners, and found that the last $100 \mathrm{~m}$ was also the slowest of the entire race, as was the last $100 \mathrm{~m}$ of elite $800-\mathrm{m}$ races (Gajer, Hanon, Marajo, \& Vollmer, 2001).

Differences in race strategy may have impact on physiological responses. In manipulating start pacing strategies during the first 4 min of a $20-\mathrm{km}$ cycling time trial, Mattern and colleagues (Mattern, Kenefick, Kertzer, \& Quinn, 2001) observed an impact both on the initial and subsequent $\mathrm{KO}_{2}$. A positive effect of an all-out pacing strategy compared with constant pacing on a 2-min paddling performance 
was reported by Bishop and colleagues (Bishop, Bonetti, \& Dawson, 2002), who thought it the result of a greater total $\mathrm{VO}_{2}$ with a similar accumulated oxygen deficit. Nevertheless, although demonstrated as optimal, these fast-start pacing strategies imply a slowing down in velocity (Gajer et al., 2001; Hanon \& Gajer, 2009) and a decrease in $\mathrm{K} \mathrm{O}_{2}$ (Billat, Hamard, Koralsztein, \& Morton, 2009; Hanon et al., 2008, 2010; Thomas et al., 2005) towards the end of races. To date, no study has compared the $\mathrm{K} \mathrm{O}_{2}$ responses of the 400-, 800-, and 1500-m race distances.

Using experimental designs based on the pacing strategies adopted during athletics events when runners realized performances equal to or very near their best, the aim of the present study was to describe and compare the effects on oxygen uptake. In light of past studies, since an aggressive pacing strategy is necessary for a best performance, and because of the supposed influence on metabolic responses, we hypothesized that the $400 \mathrm{~m}, 800 \mathrm{~m}$, and $1500 \mathrm{~m}$ could be characterized by gradual $\mathrm{V} \mathrm{O}_{2}$ responses: (1) a greater and earlier $\mathrm{KO}_{2 \text { peak }}$ when the race distance is shorter, and the start velocity greater; and (2) a greater reduction in $\mathrm{VO}_{2}$ when the race distance is short, and a higher contribution of the anaerobic metabolism to the energetic needs. To address these hypotheses, we review and synthesize data previously published by our team in scientific or technical journals.

\section{Methods}

Data from six studies by our team, undertaken between 2000 and 2008, were analysed. These studies were published as original articles in scientific (Hanon \& Gajer, 2009a; Hanon, Thomas, Leveque, \& Vivier, 2007; Hanon et al., 2008, 2010; Thomas et al., 2005) or technical publications (Gajer et al., 2001; Hanon et al., 2007), with the aim of either describing optimal pacing strategies or the consequences of them on the time course of $\mathrm{KO}_{2}$. The analyses of pacing strategies were for elite runners (allowing comparisons to be made) with the aim of achieving a best performance (Part A), whereas the ventilatory studies (Part B) were realized with nonelite runners (inter-regional or national level). To allow comparison of the 400-, 800-, and 1500-m data, new techniques have been applied that allowed modification of previously published results. In particular, the same method of determination for the reduction in $\mathrm{KO}_{2}$ (final 100-m values expressed relative to peak values) was applied to the three distances that resulted in a less marked reduction in $\mathrm{K} \mathrm{O}_{2}$ compared with the original 800-m study (24\%). Furthermore, in the 1500-m study (Hanon et al., 2008), the reduction in $\mathrm{K} \mathrm{O}_{2}$ was not reported. The three studies of Part B conformed to the recommen- dations of the Declaration of Helsinki, and participants provided voluntary written consent to participate in this experiment, which was approved by the local ethics committee.

\section{Part A: Chronometric velocity profile analysis}

Velocity profiles of elite athletes competing in the 400-, 800-, and 1500-m events have been characterized using video analysis. Three groups of 20-50 elite athletes each were used for the 400, 800, and $1500 \mathrm{~m}$. From all three groups, individuals were eliminated whose performances were $0.5 \mathrm{~s}(400 \mathrm{~m})$, $1 \mathrm{~s}(800 \mathrm{~m})$, and $1.5 \mathrm{~s}(1500 \mathrm{~m})$ below their best time and all 800- and 1500-m runners whose successive distance marks were not discernible. Finally, three groups of 5, 25, and 10 athletes were analysed for the 400, 800, and $1500 \mathrm{~m}$. The averaged performances of each group (44.4 s, $1 \mathrm{~min} 43 \mathrm{~s}$, and $3 \mathrm{~min} 35 \mathrm{~s}$ for the 400, 800, and $1500 \mathrm{~m}$ respectively) corresponded to roughly the world best performances for the athletics season considered in each study, which corresponds to 1220, 1232, and 1175 points respectively (IAAF Scoring Tables 2008, Revised Edition).

\section{Protocol}

Because races are run in lanes and the subsequent gaps between the corridors, the $400 \mathrm{~m}$ was analysed differently (additional cameras) from the $800 \mathrm{~m}$ and $1500 \mathrm{~m}$ (for more details, see Hanon \& Gajer, 2009). The $800-\mathrm{m}$ and $1500-\mathrm{m}$ analyses were based on images from personal video of national athletics coaches or from IAAF data. The times of passage were determined each $50 \mathrm{~m}(400 \mathrm{~m})$ or $100 \mathrm{~m}(800$ and $1500 \mathrm{~m}$ ) by means of a time code on the TV monitor. Sequences were digitized to register the instant at which each athlete passed the markers that had been filmed previously. The average velocity for each segment was calculated from times recorded for the 50- or 100-m segments.

\section{Part B: Ventilatory parameters}

\section{Participants}

In three different studies by our team $(2005,2008$, 2010), 10, 6, and 12 specifically trained 400-, 800-, and 1500-m runners (5-7 training sessions per week) were asked to reproduce these models of pacing strategies. These athletes were successful in regional and national running competitionss [average performance of $50.9+1.2 \mathrm{~s}$ for the men and $57.4+3.7 \mathrm{~s}$ for the two women ( $1 \mathrm{~min} 55 \mathrm{~s}+0.03 \mathrm{~s}$ and $3 \mathrm{~min} 56 \mathrm{~s}+0.21 \mathrm{~s}$ ) in the 400,800 , and $1500 \mathrm{~m}$ respectively]. 


\section{Protocol}

For all tests, oxygen uptake $\left(\mathrm{K} \mathrm{O}_{2}\right)$ was recorded continuously by means of a telemetric gas analyser (Cosmed K4, Roma, Italy) as previously described (Hanon et al., 2008, 2010; Thomas et al., 2005). Capillary blood samples were analysed with a Lactate Pro analyser (Arkray, Japan) (800 and $1500 \mathrm{~m}$ ) and a Biosen Lactate analyser (Biosen C-line analyser, EKF Industrie, Elektronik $\mathrm{GmbH}$, Barleben, Germany) (400 m).

\section{Incremental protocols}

Both $\mathrm{VO}_{2 \max }$ and $v-\mathrm{VO}_{2 \max }$ (the slowest speed at which an athlete was running when $\mathrm{K} \mathrm{O}_{2 \max }$ occurred) were determined using an incremental test conducted on an outdoor track as previously described (Hanon et al., 2008, 2010; Thomas et al., 2005).

\section{0-, 800-, and 1500-m running tests}

The warm-up was standardized based on a regular pre-event warm-up (15-20 min of jogging, stretching, and sprints at the respective start velocity). Since 400-, 800-, and 1500-m performances were different between athletes, cardiorespiratory data obtained as a function of time ( $5 \mathrm{~s}$ central moving average) were averaged over $25-\mathrm{m}$ intervals $(400 \mathrm{~m}, 800 \mathrm{~m})$ or 50 -m intervals $(1500 \mathrm{~m})$. The highest 5 -s value for

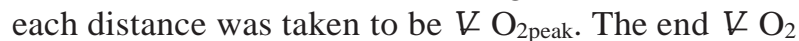
( $\mathrm{K} \mathrm{O}_{2 \text { end }}$ ) value was defined as the average of the last 100-m values, and the decrease in $\mathrm{KO}_{2}\left(\mathrm{~V} \mathrm{O}_{2 \text { decrease }}\right)$ was defined as the difference between $\mathrm{V} \mathrm{O}$ 2peak and $\mathrm{VO}_{2 \text { end }}$ expressed relative to the peak values. Blood samples were taken from the ear lobe just before the tests and then at 1, $4(400 \mathrm{~m}), 3$ and 5 (800 and $1500 \mathrm{~m})$, and 7 and $10 \mathrm{~min}$ (400, 800, $1500 \mathrm{~m}$ ) during a passive recovery. The start and final velocities corresponded to the mean velocity during the first and the last 100-m segments. The velocity measured at $25 \%$ was the average velocity during the $25-\mathrm{m}(400 \mathrm{~m}, 800 \mathrm{~m})$ or $50-\mathrm{m}(1500 \mathrm{~m})$ segment preceding 100, 200, and $350 \mathrm{~m}$ after the onset of the test for the 400, 800, and $1500 \mathrm{~m}$ respectively.

\section{Statistic analysis}

Data are reported as means + standard deviations (s). Relationships between variables (running velocity at different times of the race, metabolic parameters, and $\mathrm{KO}_{2}$ kinetics) were analysed by Pearson's correlation coefficient. The relationship between blood lactate concentration $(x)$ and the decrease/ increase in $\mathrm{KO}_{2}(y)$ was assessed by regression analysis. All statistical analyses were conducted using Statview software (version 5.0). Statistical significance was set at $P 50.05$.

\section{Results}

\section{Part A: Chronometric velocity profile analysis}

As shown in Table I, and in spite of the start inertia, the start velocities recorded during the three races were always faster than the respective mean velocity. For the 400- and 800-m distances (Figure 1), peak velocities were reached early during the first $(400 \mathrm{~m})$ and second $100 \mathrm{~m}(800 \mathrm{~m})$, although the fastest $100 \mathrm{~m}$ was covered between 1200 and $1300 \mathrm{~m}$ of the $1500-\mathrm{m}$ distance. The velocity in the last $100 \mathrm{~m}$ decreased significantly in the 400-, 800-, and $1500-\mathrm{m}$ races and was the slowest of the segments in the 400 and $800 \mathrm{~m}$. Expressed relative to the peak value, the slowest final $100 \mathrm{~m}$ was observed for the shortest distance (Table I).

As observed in Table II and Figure 2, $\mathrm{K} \mathrm{O}_{2 \text { peak }}$ was higher and reached later when the distance run was long. A decrease in $\mathrm{VO}_{2}$ when the distance was short was observed in all participants in the $400-$ and $800-\mathrm{m}$ races and in 9 of 12 participants in the $1500 \mathrm{~m}$. Furthermore, a decrease in average tidal volume was systematically observed for all three distances. A decrease in minute ventilation was observed in the $400 \mathrm{~m}$ and $800 \mathrm{~m}$ and a decrease in respiratory frequency was noted in the $400 \mathrm{~m}$ only (Figure 3). There was a strong correlation between $\mathrm{KO}_{2}$ and tidal volume recorded during the last $100 \mathrm{~m}$ of each race

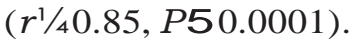

\section{Part B: Ventilatory parameters}

The velocity measured at $25 \%$ of the distance ( 100 , 200 , and $350 \mathrm{~m}$ after the onset of the test for the 400 ,

Table I. Start and final velocities.

\begin{tabular}{lrrr}
\hline & $400 \mathrm{~m}$ & $800 \mathrm{~m}$ & $1500 \mathrm{~m}$ \\
\hline Mean velocity $\left(\mathrm{m} \cdot \mathrm{s}^{71}\right)$ & 8.99 & 7.76 & 6.97 \\
First $100 \mathrm{~m}\left(\mathrm{~m} \cdot \mathrm{s}^{\prime 1}\right)$ & 9.06 & 7.86 & 7.35 \\
Segment time $(\mathrm{s})$ & 11.04 & 12.73 & 13.61 \\
Last $100 \mathrm{~m}\left(\mathrm{~m} \cdot \mathrm{s}^{71}\right)$ & 8.12 & 7.32 & 7.13 \\
Segment time $(\mathrm{s})$ & 12.31 & 13.65 & 14.02 \\
Last $100 \mathrm{~m}(\%)$ & 76.60 & 88.40 & 95.94
\end{tabular}

Note: Velocity $\left(\mathrm{m} \cdot \mathrm{s}^{71}\right)$ is measured over the complete distance (mean velocity) and over the first and last $100 \mathrm{~m}$ of each distance. The first and the last 100-m segment times (s) correspond to the times to cover the first and the last $100 \mathrm{~m}$ of each distance. The last $100 \mathrm{~m}$ is expressed (\%) relative to the fastest portion $(50 \mathrm{~m}$ for the $400 \mathrm{~m} ; 100 \mathrm{~m}$ for the $800 \mathrm{~m}$ and $1500 \mathrm{~m}$ ) of each corresponding distance. 


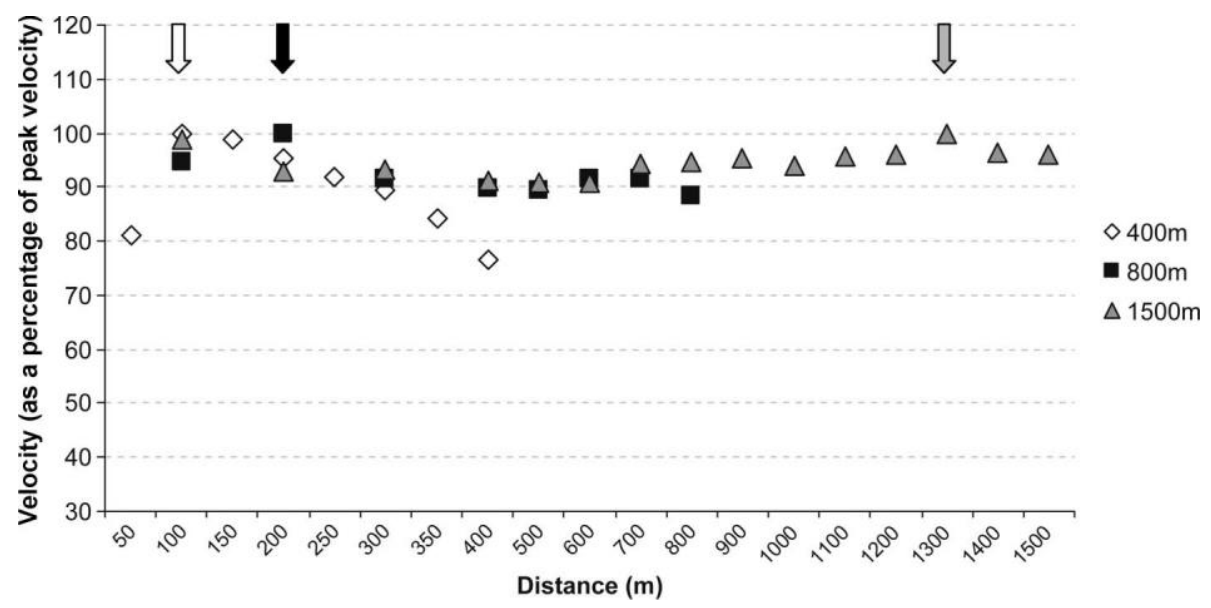

Figure 1. Time course of velocity during the 400-, 800-, 1500-m running elite competitions. Velocities expressed relatively to the peak of velocity of each distance (white, grey and black symbols correspond to 400, 800 and $1500-\mathrm{m}$ velocities and respective arrow correspond to 400, 800 and 1500-m peak velocities). The 400, 800 and 1500-m velocities are presented every 25,50 and $100 \mathrm{~m}$, respectively.

Table II. Peak values measured during (cardiorespiratory variables) and after (blood lactate concentration) the 400-, 800-, and 1500-m tests $($ mean $+s)$.

\begin{tabular}{|c|c|c|c|c|c|}
\hline & $\begin{array}{c}\mathrm{V} \mathrm{O}_{2 \text { peak }} \\
\left(\mathrm{ml} \cdot \mathrm{kg}^{71} \cdot \min ^{71}\right)\end{array}$ & $V \mathrm{O}_{2 \text { peak }}\left(\% V \mathrm{O}_{2 \max }\right)$ & $\begin{array}{l}\text { Distance at } \\
\mathrm{VO}_{2 \text { peak }}(\mathrm{m})\end{array}$ & $\begin{array}{c}\mathrm{V} \mathrm{O}_{2 \text { decrease }} \\
\left(\% \mathrm{~V} \mathrm{O}_{2 \text { peak }}\right)\end{array}$ & $\begin{array}{l}\text { Peak lactate } \\
\left(\mathrm{mmol} \cdot \mathrm{l}^{71}\right)\end{array}$ \\
\hline $400 \mathrm{~m}$ & $54.2+5.7$ & $93.9+3.9$ & $192+22$ & $15.6+6.5$ & $22.0+1.9$ \\
\hline $800 \mathrm{~m}$ & $66.3+2.3$ & $103.3+3.8$ & $316+75$ & $9.9+6.3$ & $17.8+1.4$ \\
\hline $1500 \mathrm{~m}$ & $69.2+6.5$ & $105.1+10.5$ & $459+59$ & $3.6+7.6$ & $14.9+0.9$ \\
\hline
\end{tabular}

Note: $\mathrm{KO}_{2 \text { peak }}$ was determined as the highest 5-s central moving average. $\mathrm{KO}_{2 \text { decrease }}$ is expressed relative to the peak values defined as the difference between the $\mathrm{KO}_{2 \text { peak }}$ and $\mathrm{KO}_{\text {2end }}$.

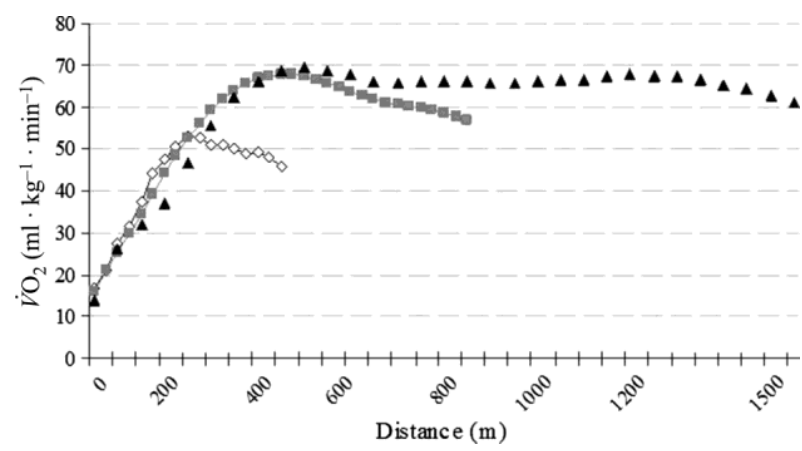

Figure 2. Time course of $\mathrm{KO}_{2}$ during the 400-m(\}), 800-m(a), and 1500-m( ) running tests.

800 , and $1500 \mathrm{~m}$ respectively) was the parameter most strongly correlated with the time to reach $\mathrm{KO}_{\text {2peak. The time to reach }} \mathrm{KO}_{\text {2peak }}$ was shorter when the start velocity at $25 \%$ of the distance was high $\left(r \frac{1}{4} 70.79, P 50.0001\right)$. Other correlations $(12 \%, 5 \%$, and $33 \%$ of the distance) with time to reach $\mathrm{KO}_{2 \text { peak }}$ were calculated but found to be weaker $(P 50.0005$ and $P 50.005$ respectively). The amplitude of the decrease in $\mathrm{KO}_{2}$ was related to peak blood lactate concentration measured after

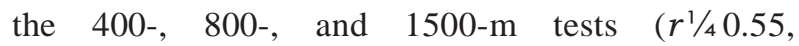
$P 50.005, n^{1 / 428)}$ but no relation was observed between velocity and decrease in $\mathrm{KO}_{2}\left(r^{1 / 40.29)}\right.$. In the 1500-m runners, the decrease in $\mathrm{K} \mathrm{O}_{2}$ was correlated with the velocity at $25 \%$ of the distance covered (measured between 300 and $350 \mathrm{~m}$ ) expressed as a percentage of $v-\mathrm{KO}_{2 \max }\left(r^{1 / 1} / 40.59\right.$, $P 50.05)$. The significant relationship between the magnitude of the decrease/increase in $V \mathrm{O}_{2}$ and peak lactate concentrations post-race $\left(r^{1 / 4} 0.55\right.$, $\left.P 50.005, r^{2} 1 / 40.30\right)$ indicates that $10 \mathrm{mmol} \cdot \mathrm{L}^{71}$ is the minimum value under which no decrease in $V \mathrm{O}_{2}$ is likely to occur in such exercise (Figure 4) and that blood lactate concentration can explain $30 \%$ of the magnitude of the decrease in $\mathrm{KO}_{2}$.

\section{Discussion}

Athletics distances of 400,800 , and $1500 \mathrm{~m}$ are characterized by common (fast-start) but also distinct (final velocity) characteristics, making them unique in their own way. From 400 to $1500 \mathrm{~m}$, the links between pacing strategies and $\mathrm{VO}_{2}$ are clearly demonstrated: (1) a strong relationship between the velocities measured at $25 \%$ of each distance and the time to reach $\mathrm{KO}_{\text {2peak }}$, and (2) the occurrence of a decrease in $\mathrm{VO}_{2}$ that is related to the final peak lactate concentration. 

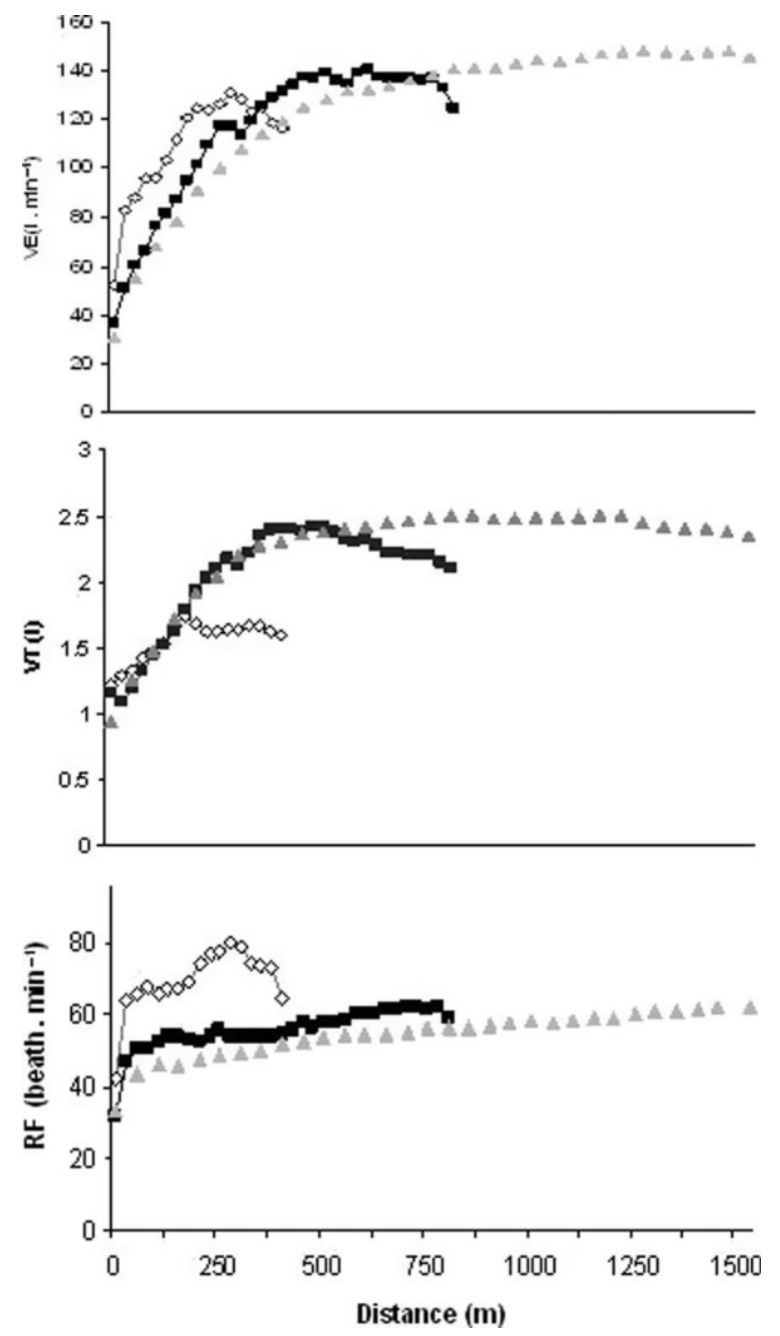

Figure 3. Ventilatory parameters time course during 400, 800 and 1500-m running tests. RF: respiratory frequency, VT: tidal volume, VE: minute ventilation measured during the 400-m (\}), 800-m (\&) and 1500-m ( $\Delta$ ) distances.

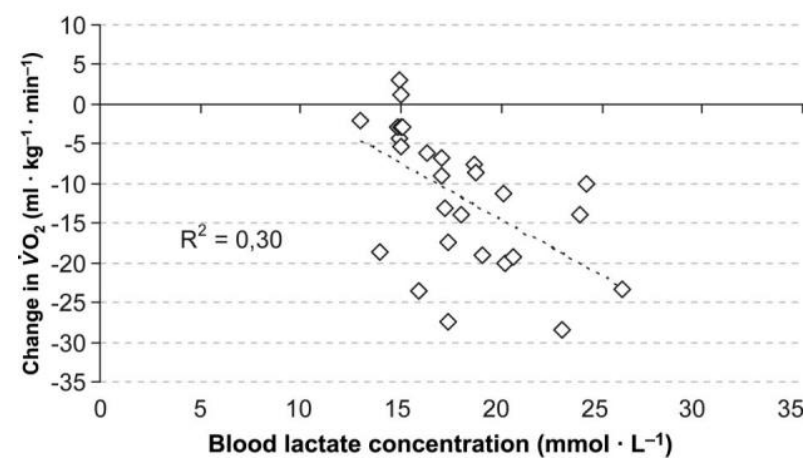

Figure 4 . Blood lactate concentration $\left(\mathrm{mmol} \cdot \mathrm{L}^{71}\right)$ vs. change in $\mathrm{VO}_{2}\left(\mathrm{ml} \cdot \mathrm{kg}^{71} \cdot \min ^{71}\right)$.

\section{Consequence of the startvelocity}

The pacing strategies used by elite 400-, 800-, and 1500-m runners show some common characteristics, such as a fast start and a slowing of velocity in the last 100 m (Gajer et al., 2001; Hanon \& Gajer, 2009;
Hanon et al., 2007). However, whereas no acceleration was observed in the second half of the 400- and $800-\mathrm{m}$ races, peak velocity in the $1500 \mathrm{~m}$ was observed $300 \mathrm{~m}$ before the finish line.

In contrast, in studies performed on a treadmill at average constant velocity (Draper \& Wood, 2005; Draper, Wood, \& Fallowfield, 2003; Spencer \& Gastin, 2001), $\mathrm{K} \mathrm{O}_{2}$ has previously been shown to be at or close to maximum (Duffield, Dawson, \& Goodman, 2005a, 2005b; Hanon et al., 2008, 2010; Thomas et al., 2005) in races of 400 to $1500 \mathrm{~m}$ using this positive (athlete's speed gradually declines) pacing strategy. Some authors have tested the positive effect of this pacing on the amplitude of $\mathrm{KO}_{\text {2peak, }}$, which results in a better performance in 2-min paddling (Bishop et al., 2002), running (Gastin, Costill, Lawson, Krzeminski, \& McConell, 1995; Sandals, Wood, Draper, \& James, 2006), and 60-s cycling (de Koning et al., 1999) exercises. The correlation $\left(r^{1 / 4} 70.79, P 50.0001\right)$ observed in the present study between the velocity at $25 \%$ of each distance and the time to reach $V_{\text {2peak }}\left(r^{1 / 4} 70.79\right.$, $P 50.0001)$ is in agreement with the literature (Åstrand \& Saltin, 1961; Hill, 1999). Therefore, this positive or "all-out' pacing strategy appears necessary to reach a high relative $K \mathrm{O}_{2}$ in such a short time, and to realize one's best performance.

\section{Decrease in $\mathrm{VO}_{2}$ in the last part of the races}

In our three previous studies, a decrease in $\mathrm{VO}_{2}$ was observed in the final part of the race whereas the velocity was always greater than $v-V \mathrm{O}_{2 \max }$ for all participants, even in the last $100 \mathrm{~m}$ of the 400-, 800-, and $1500-\mathrm{m}$ distances. Whereas this phenomenon was observed in every runner in the 400 and $800 \mathrm{~m}$, this decrease was less marked and not systematic in the $1500 \mathrm{~m}$ (Billat et al., 2009; Hanon et al., 2007). This decrease in $\mathrm{KO}_{2}$ was shown to be related to the final decrease in velocity over the 400- and 800-m distances but not the 1500-m study, no more than observed in the total population $(400,800$, and $1500 \mathrm{~m}$ ). Nevertheless, for the $1500 \mathrm{~m}$, this final $\mathrm{VO}_{2}$ response was correlated with the velocity at $25 \%(300-350 \mathrm{~m})$ expressed as a percentage of $v$ $\mathrm{V} \mathrm{O}_{2 \max }$, indicating that the outcome of pacing depends on the duration of the race, with the $1500 \mathrm{~m}$ being regulated differently than the 400 and $800 \mathrm{~m}$. Furthermore, as a decrease has previously been reported (Nummela \& Rusko, 1995) and studied (Perrey, Candau, Millet, Borrani, \& Rouillon, 2002) at a constant pace on exhaustive treadmill running tests, causality cannot be inferred in the relationship between the decrease in velocity and decrease in $\mathrm{VO}_{2}$. During treadmill running tests to exhaustion, biomechanical adaptations such as a decrease in stride length are possible (Hanon, 
Thepaut-Mathieu, \& Vandewalle, 2005). This decrease in stride length could be the result of a progressive failure to produce force (Taylor, Bronks, Smith, \& Humphries, 1997), since Nummela and colleagues (Nummela, Vuorimaa, \& Rusko, 1992) found that drop-jump performance was impaired by *39\% following a maximal 400-m sprint, during which a decrease in stride length was observed. The significant correlation between the magnitude of decrease in $\mathrm{KO}_{2}$ and blood lactate concentration observed in the present study suggests that this phenomenon is related to the high glycolytic contribution and therefore to a high level of fatigue, as shown by the decrease in stride length and/or stride frequency. To reinforce this result, a correlation was observed between $\mathrm{pH}$ values and the final $\mathrm{KO}_{2}$ in the 400-m race (Hanon et al., 2010). Based on the present results and those in the literature (Billat et al., 2009; Nummela \& Rusko, 1995), a large glycolytic contribution could partly explain why a decrease in $\mathrm{VO}_{2}$ is likely to occur during short and intense exercise. This relationship between the magnitude of the decrease in $\mathrm{K} \mathrm{O}_{2}$ and blood lactate concentration could explain the absence of a decrease in $\mathrm{KO}_{2}$ with a less aggressive pacing strategy (Duffield, Dawson, \& Goodman, 2004; Duffield et al., 2005b; James, Sandals, Draper, Maldonado-Martin, \& Wood, 2007). One can then postulate that the reductions in $\mathrm{K} \mathrm{O}_{2}$ and velocity (or only stride length) are both the consequences of extreme fatigue.

Furthermore, the strong positive relationship observed between tidal volume and $\mathrm{K} \mathrm{O}_{2}$ recorded during the last $100 \mathrm{~m}$ of the three races could be a consequence of the hyperpnoea due to metabolic acidosis (Forster \& Pan, 1995). These results could indicate that the runners hyperventilated so as to partially compensate for their metabolic acidosis and to maintain an effective alveolar $\mathrm{O}_{2}$ pressure (Miyachi \& Katayama, 1999). This decrease in tidal volume associated with an increase in breathing frequency, observed for the 800- and 1500-m distances, was reported previously by Cibella and colleagues (Cibella et al., 1996), during exhaustive exercise under chronic hypoxia, and by Perrey et al. (2002) in participants who demonstrated a decrease in $\mathrm{KO}_{2}$. Gallagher and colleagues (Gallagher, Im Hof, \& Younes, 1985) have shown that this particular respiratory pattern observed during exhausting exercise could be considered an indirect sign of respiratory fatigue. Nevertheless, it is noteworthy that decreases in all ventilatory parameters (minute ventilation, breathing frequency, and tidal volume) were observed in the 400-m runners, demonstrating another respiratory pattern.

\section{Why is this pacing strategy the most efficient?}

This pacing strategy also possesses the potential to cause premature fatigue because of disturbances in muscle $\mathrm{pH}$. This acidosis has been shown to inhibit aerobic capacity (Jubrias, Crowther, Shankland, Gronka, \& Conley, 2003) and to cause low final $\mathrm{KO}_{2}$ values (Hanon et al., 2010; Thomas et al., 2005). As reported by Foster et al. (1994), athletes learn how to sense low muscle $\mathrm{pH}$ and adjust their pace accordingly, so that they ideally reach critical low values of $\mathrm{pH}$ near the end of a race. Interestingly, in 1997, Kipketer beat the 800$m$ world record when using this pacing strategy. The pacing strategies described in this study confirm the model based on the two equations derived from Newton's second law and that for power balance of metabolism described by Maronski (1996). In this model, the author concluded that the optimal tactic for performance over these intermediate distances, which are neither sprints nor long-distance events, is an initial acceleration phase and a final reduction in velocity.

Based on the intermediate $\mathrm{pH}$ values recorded for the $400 \mathrm{~m}$ (Hanon et al., 2010), well-trained athletes appear to be able to run about $15 \mathrm{~s}$ with a $\mathrm{pH}$ of 7.1 , but must reduce the pace when $\mathrm{pH}$ falls below 7.0. Many authors (Abbiss \& Laursen, 2008; Billat et al., 2009; de Koning et al., 1999; Foster et al., 1994; Hettinga, De Koning, Broersen, Van Geffen, \& Foster, 2006) have concluded that anaerobic resources seem to be critical in regulating pacing strategies. Successful performance on the $400 \mathrm{~m}$ and $800 \mathrm{~m}$ requires full use of the buffering capacity (Ward-Smith, 1999), and therefore critical final values of $\mathrm{pH}$ (Foster et al., 1994). To accelerate in the last straight line is not compatible with these criteria, and does not allow a best performance.

The 1500-m distance appears to be regulated differently from the shorter distances as there was a significant and negative relationship between start velocity, expressed as a percentage of $v-V \mathrm{O}_{2 \max }$ and final performance. This result is in good agreement with the conclusions of Billat et al (2009), who demonstrated that $1500-\mathrm{m}$ runners who had the longest limits at their anaerobic power in the first part of the race (that is, close to the present notion of velocity expressed as a percentage of $v-V \mathrm{O}_{2 \max }$ ) were those who achieved the best final performance. As in Billat and colleagues' study, this relation was obtained only in the $1500 \mathrm{~m}$, which indicates a different pacing regulation compared with the shorter distances. Furthermore, the difference in competitive standard of participants (more than $20 \mathrm{~s}$ between the present study and that of Billat et al., 2009) could indicate that this result depends on the 
duration of exercise rather than on the standard of competition.

\section{Conclusions}

When exercise is less than $3 \mathrm{~min} 30 \mathrm{~s}$, the only way to ensure the total depletion of anaerobic reserves is to reach the exact sustainable $\mathrm{pH}$ value at the finish line. It appears that this is only possible with a fast start and a slowing of velocity in the last metres of the race, as calculated by Maronski (1996). The decrease in $\mathrm{VO}_{2}$ observed in the final stages of the three events examined here appears to be a consequence of aggressive pacing strategies and, therefore, extreme exhaustion. The high correlation between the decreases in $\mathrm{KO}_{2}$ and tidal volume indicates that ventilatory regulation likely induced by metabolic $\mathrm{HP}$ accumulation is the major cause of the decrease in $\mathrm{KO}_{2}$. The $1500 \mathrm{~m}$, which is regulated differently from the shorter distances, appears to be intermediate between predominantly anaerobic distances (400- and 800-m races) and predominantly aerobic middle- and long-distance running.

\section{Acknowledgements}

This research was supported by the French Ministry of Health, Youth and Sport.

\section{References}

Abbiss, C.R., \& Laursen, P.B. (2008). Describing and understanding pacing strategies during athletic competition. Sports Medicine, 38, 239-252.

Åstrand, P.O., \& Saltin, B. (1961). Maximal oxygen uptake and heart rate in various types of muscular activity. Journal of Applied Physiology, 16, 977-981.

Billat, V., Hamard, L., Koralsztein, J.P., \& Morton, R.H. (2009). Differential modeling of anaerobic and aerobic metabolism in the 800-m and 1,500-m run. Journal of Applied Physiology, 107, 478-487.

Bishop, D., Bonetti, D., \& Dawson, B. (2002). The influence of pacing strategy on $\mathrm{V} \mathrm{O} \mathrm{O}_{2}$ and supramaximal kayak performance. Medicine and Science in Sports and Exercise, 34, 1041-1047.

Cibella, F., Cuttitta, G., Kayser, B., Narici, M., Romano, S., \& Saibene, F. (1996). Respiratory mechanics during exhaustive submaximal exercise at high altitude in healthy humans. Journal of Physiology, 494, 881-890.

de Koning, J.J., Bobbert, M.F., \& Foster, C. (1999). Determination of optimal pacing strategy in track cycling with an energy flow model. Journal of Science and Medicine in Sport, 2, 266-277.

Draper, S.B., \& Wood, D.M. (2005). The $\mathrm{K} \mathrm{O}_{2}$ response for an exhaustive treadmill run at $800-\mathrm{m}$ pace: A breath-by-breath analysis. European Journal of Applied Physiology, 93, 381-389.

Draper, S.B., Wood, D.M., \& Fallowfield, J.L. (2003). The $\mathrm{V} \mathrm{O}_{2}$ response to exhaustive square wave exercise: Influence of exercise intensity and mode. European Journal of Applied Physiology, 90, 92-99.

Duffield, R., Dawson, B., \& Goodman, C. (2004). Energy system contribution to $100-\mathrm{m}$ and $200-\mathrm{m}$ track running events. Journal of Science and Medicine in Sport, 7, 302-313.
Duffield, R., Dawson, B., \& Goodman, C. (2005a). Energy system contribution to 400-metre and 800-metre track running. Journal of Sports Sciences, 23, 299-307.

Duffield, R., Dawson, B., \& Goodman, C. (2005b). Energy system contribution to 1500 - and 3000-metre track running. Journal of Sports Sciences, 23, 993-1002.

Foster, C., Schrager, M., \& Snyder, A.C. (1994). Pacing strategy and athletic performance. Sports Medicine, 17, 77-85.

Forster, H.V., \& Pan, L.G. (1995). Contribution of acid-base changes to control of breathing during exercise. Canadian Journal of Applied Physiology, 20, 380-394.

Gajer, B., Hanon, C., Marajo, J., \& Vollmer, J.C. (2001). Le 800 mètres: Analyse descriptive et entraînement. Paris: Edition INSEP-Federation Française d'Athlétisme, Collection Entrâ̂nement.

Gallagher, C.G., Im Hof, V., \& Younes, M. (1985). Effect of inspiratory muscle fatigue on breathing pattern. Journal of Applied Physiology, 59, 1152-1158.

Gastin, P.B., Costill, D.L., Lawson, D.L., Krzeminski, K., \& McConell, G.K. (1995). Accumulated oxygen deficit during supramaximal all-out and constant intensity exercice. Medicine and Science in Sports and Exercise, 27, 255-263.

Hanon, C., \& Gajer, B. (2009). Velocity and stride parameters of world-class 400-meter athletes compared with less experienced runners. Journal of Strength and Conditioning Research, 23, 524531.

Hanon, C., Lepretre, P.M., Bishop, D., \& Thomas, C. (2010). Oxygen uptake and blood metabolic responses to a 400-m run. European Journal of Applied Physiology, 109, 233-240.

Hanon, C., Leveque, J.M., Thomas, C., \& Vivier, L. (2008). Pacing strategy and $\mathrm{VO}_{2}$ kinetics during a $1500-\mathrm{m}$ race. International Journal of Sports Medicine, 29, 206-211.

Hanon, C., Thepaut-Mathieu, C., \& Vandewalle, H. (2005). Determination of muscular fatigue in elite runners. European Journal of Applied Physiology, 94, 118-125.

Hanon, C., Thomas, C., Leveque, J.M., \& Vivier, L. (2007). Time course of velocity and oxygen uptake during 1500-m realized with a strategy of best chronometric performance. New Studies in Athletics, 22, 115-122.

Hettinga, F.J., De Koning, J.J., Broersen, F.T., Van Geffen, P., \& Foster, C. (2006). Pacing strategy and the occurrence of fatigue in 4000-m cycling time trials. Medicine and Science in Sports and Exercise, 38, 1484-1491.

Hill, D.W. (1999). Energy system contributions in middledistance running events. Journal of Sports Sciences, 17, 477-483.

James, D. V., Sandals, L. E., Draper, S. B., Maldonado-Martin, S., \& Wood, D. M. (2007). $\mathrm{KO}_{2}$ attained during treadmill running: The influence of a specialist $(400-\mathrm{m}$ or $800-\mathrm{m})$ event. International Journal of Sports Physiology and Performance, 2, 128-136.

Jubrias, S.A., Crowther, G.J., Shankland, E.G., Gronka, R.K., \& Conley, K.E. (2003). Acidosis inhibits oxidative phosphorylation in contracting human skeletal muscle in vivo. Journal of Physiology, 553, 589-599.

Lacour, J.R., Bouvat, E., \& Barthélémy, J.C. (1990). Postcompetition blood lactate concentrations as indicators of anaerobic energy expenditure during 400-m and 800-m races. European Journal of Applied Physiology, 61, 172-176.

Maronski, R. (1996). Minimum-time running and swimming: An optimal approach. Journal of Biomechanics, 29, 245-249.

Mattern, C.O., Kenefick, R.W., Kertzer, R., \& Quinn, T.J. (2001). Impact of starting strategy on cycling performance. International Journal of Sports Medicine, 22, 350-355.

Miyachi, M., \& Katayama, K. (1999). Effects of maximal interval training on arterial oxygen desaturation and ventilation during heavy exercise. Japanese Journal of Physiology, 49, 401-407. 
Nummela, A., \& Rusko, H. (1995). Time course of anaerobic and aerobic energy expenditure during short-term exhaustive running in athletes. International Journal of Sport Medicine, 16, 522-527.

Nummela, A., Vuorimaa, T., \& Rusko, H. (1992). Changes in force production, blood lactate and EMG activity in the 400-m sprint. Journal of Sports Sciences, 10, 217-228.

Perrey, S., Candau, R., Millet, G.Y., Borrani, F., \& Rouillon, J.D. (2002). Decrease in oxygen uptake at the end of high-intensity submaximal running in humans. International Journal of Sport Medicine, 23, 298-304.

Sandals, L.E., Wood, D.M., Draper, S.B., \& James, D.V. (2006). Influence of pacing strategy on oxygen uptake during treadmill middle-distance running. International Journal of Sport Medicine, 27, 37-42.

Spencer, M.R., \& Gastin, P.B. (2001). Energy system contribution during 200 - to $1500-\mathrm{m}$ running in highly trained athletes. Medicine and Science in Sports and Exercise, 33, 157-162.

Taylor, A.D., Bronks, R., Smith, P., \& Humphries, B. (1997). Myoelectric evidence of peripheral muscle fatigue during exercise in severe hypoxia: Some references to $\mathrm{m}$. vastus lateralis myosin heavy chain composition. European Journal of Applied Physiology and Occupational Physiology, 75, 151-159.
Thomas, C., Hanon, C., Perrey, S., Le Chevalier, J.M., Couturier, A., \& Vandewalle, H. (2005). Oxygen uptake response to an 800$\mathrm{m}$ running race. International Journal of Sports Medicine, 26, 268-273.

Tucker, R., Lambert, M., \& Noakes, T.D. (2006). An analysis of pacing strategies during men's World-record performances in track athletics. International Journal of Sport Physiology and Performance, 1, 223-245.

Tucker, R., \& Noakes, T.D. (2009). The physiological regulation of pacing strategy during exercise: A critical review. British Journal of Sports Medicine, 43(6), e1.

Ward-Smith, A.J. (1999). Aerobic and anaerobic energy conversion during high-intensity exercise. Medicine and Science in SportsandExercise, 31, 1855-1860. 